\title{
Study of the Effect of Repetitive Transcranial Magnetic Stimulation on a Sample of Children with Attention-Deficit/Hyperactivity Disorder
}

\author{
Abdullah Ahmed Abdullah Mekky, Amgad Ahmed Moshref Gabr, Mohamed Ahmed Lotfy \\ Kamal, Mohamed Mahmoud Hamouda and Ahmed Said Abd El Khalik Khalil* \\ Department of Psychiatry, Faculty of Medicine, Al-Azhar University, Cairo, Egypt \\ Corresponding author: Ahmed Said Abd El Khalik Khalil,email: drahmedsaid8@gmail.com, mobile:01062915246.
}

\begin{abstract}
Background: attention Deficit Hyperactivity Disorder (ADHD) is one of the most common neuropsychiatric disorder that affects children and young adults and cause significant functional impairment. Although there are effective medications and psychobehavioural therapies that help with management of ADHD, the medications can have significant side effects, which limit their use. There is need to explore other treatment options. transcranial magnetic stimulation (TMS) and repetitive transcranial magnetic stimulation (rTMS) are recent safe and non-invasive investigative and therapeutic tools. Aim of the work: to study the effect of repetitive transcranial magnetic stimulation on a sample of children with Attention-Deficit/Hyperactivity Disorder. Methods: the sample was consisted of (35) child; their ages were ranged from 6 to 12 years old after diagnosed clinically according to DSM-5 through a designed semi structured interview and through application of Conner's teacher- 28 and parent-48 rating scales as ADHD combined type. Females were (11) children with percentage $31.4 \%$, while males were (24) children with percentage $68.6 \%$. All patients on the sample were not receiving any medical or behavioral therapy for ADHD. Results: means scores of inattention, hyperactivity and impulsivity were reduced significantly in the post 5 days and 2 weeks follow up (P-values $<0.001$ ), started to rise again in its evaluation after 4 weeks but not reaching its values before rTMS sessions. the percentage of severe cases in each scale category was dramatically decreased immediately and 2 weeks after rTMS sessions and started to rise again in its evaluation after 4 weeks but to lower percent than before rTMS sessions $(70 \%, 100 \%$ and $60 \%$ had severe inattention, hyperactivity and impulsivity respectively before rTMS, reduced to $0 \%, 0 \%, 10 \%$ immediately and 2 weeks after rTMS but increased to $(20 \%, 40 \%$ and $40 \%)$ after 4 weeks. no patient experienced any significant adverse effects during the study, except 3 children reported mild headache that resolved spontaneously within an hour without medication. Conclusion: this study concluded that $r$ TMS over left dorso-lateral prefrontal cortex may be safe and effective way of providing relatively lasting relief of ADHD symptoms especially in children with severe symptoms.
\end{abstract}

Key words: ADHD - neurobiology - TMS - rTMS.

\section{Introduction}

\section{Attention Deficit/Hyperactivity}

Disorder (ADHD) is the most common neurobehavioral disorder during childhood that affects $5-12 \%$ in school age children. Male to female ratio is around $3: 1$ in children \& adolescents. Approximately 8-10\% of males \& 3-4 \% of females under the age of 18 suffer from ADHD ${ }^{(\mathbf{1})}$. Prospective study show ADHD symptoms continue in $60 \%$ of the children who has this disorder even after their puberty ${ }^{(2)}$. According to the Fifth Edition of American Psychiatric Association's Diagnostic Statistical Manual of mental disorders (DSM 5), ADHD is defined as developmentally inappropriate levels of inattention, hyperactivity, and/or impulsivity which result in functional impairments in multiple settings, thus affects family, academic and social aspects ${ }^{(3)}$.
ADHD is a multifactorial disorder associated with environmental and genetic factors ${ }^{(4)}$. Dopamine alteration is believed to be the main neurochemical underlying its pathophysiology ${ }^{(5)}$ and deficient inhibitory control is the characteristic of children with this disorder. Based on these facts, brain stimulants are, to date, the most successful as well as the most controversial therapy employed. Despite the enormous amount of research done, clinicians and parents are eagerly waiting for additional and better therapeutic options.

Studies show that other psychiatric disorders are more common in ADHD patients such as anxiety disorders, mood disorders, impulse control disorder, substance abuse, personality disorders especially antisocial personality and learning disabilities. And some 
of these disorders are duo to direct reflection to ADHD and other disorders has the same risk factors as $\mathrm{ADHD}{ }^{(6)}$. One of the most common comorbid disorders with ADHD is conduct disorder and these children have both ADHD and conduct disorder are more susceptible to get more psychiatric disorders that affect their whole life like drug abuse and disturbed behavior more than ADHD children and control sample ${ }^{(7)}$.

Studies have shown that the left hemisphere is involved in attentional dysfunction in children with ADHD with decreased activation of the left Dorsolateral Prefrontal Cortex (middle frontal gyrus, BA 46, 9, 8), superior parietal cortex (postcentral gyrus, BA 6, 4, 2, 1, 7), and subcortical structures involved in fronto-striatal loops ${ }^{(8)}$. Hyperactivity, a common feature of ADHD, particularly in children, has been shown to be related to abnormalities in the motor systems such as poor motor inhibition. Reduced activity in primary motor cortex (BA4) as well as in sensory cortex during simple motor tasks in ADHD patients has been reported (9). Impulsivity is related to changes in reward processing and behavioral inhibition. Failure of these processes is manifested as impulsivity. fMRI studies have shown decreased activation of the right inferior frontal gyrus, right supplementary motor area (BA6) and anterior cingulate (BA 32), right fusiform gyrus (BA 19), left caudate head, and right thalamus during motor inhibition tasks (Go-NoGo or Stop signal tasks) in ADHD patients ${ }^{(\mathbf{1 0})}$.

Magnetic stimulation is a recent and powerful non-invasive tool developed for studying the nervous system. It is believed that rTMS affects gene expression (11), neuronal plasticity, dopamine release ${ }^{(12)}$, and release of endogenous opioids ${ }^{(13)}$. It is also currently being used to treat brain diseases, improving functional deficits and achieving promising results in recent years ${ }^{(\mathbf{1 4})}$. It is a useful tool that increases our understanding of ADHD pathophysiology (15) (16). Dorsolateral prefrontal cortex (DLPFC) is believed to be highly involved in the pathophysiology of ADHD. There seem at least three distinct circuits to be involved of in ADHD patho-physiology: lateral attentional network, medial reward-related network, and fronto-cerebellar time-processing network ${ }^{(17)}$.
Based on previously mentioned functional neuroanatomy, potential accessible candidate targets for $\mathrm{r}$ TMS are represented by dorsolateral prefrontal cortex, ventrolateral prefrontal cortex, inferior frontal gyrus, dorsal parts of supplementary motor cortex, and cerebellum. Modulation of dorsolateral prefrontal cortex may lead to changes of attention, working memory, and executive functions and through the top-down regulations it may exert effects on emotional dysregulation symptoms, and impulsivity. Inferior frontal gyrus stimulation may lead to changes in behavioral inhibition and time processing. Cerebellar stimulation may affects time processing, cognitive functioning, and may be the affective symptoms of ADHD ${ }^{(18)}$ and we expect that if the rTMS effects on the dopaminergic system found in normal individuals can be replicated in ADHD patients ${ }^{(19)}$, it could be the first step in offering new hope to patients, researchers and clinicians in the treatment of ADHD.

Aim of the work: to study the effect of repetitive transcranial magnetic stimulation on a sample of children with AttentionDeficit/Hyperactivity Disorder who attended to Al-Azhar university specialized hospital, in the period from January 2018 to June 2018.

\section{Patients and Methods}

This prospective study was conducted at Al-Azhar University specialized hospital (Bab Al Shearia hospital) where (35) child, were chosen randomly who came to Psychiatry clinic in Bab Al Shearia hospital, Al-Azhar university in the period from January 2018 to June 2018 to seek medical help and to complain about some behavioral and study problems and their age were range from 6 to 12 years old. After diagnosed clinically according to DSM-5 through a designed semi structured interview and through application of Conner's teacher-28, parent-48 rating scales ${ }^{(20)}$ as ADHD combined type patients. And female children were (11) children with percentage $31.4 \%$, while male children were (24) children with percentage $68.6 \%$. All patients on the sample are not receiving any medical or behavioral therapy for ADHD. All patients' parents signed an informed written consent after explanation of the aim of the study and the study details and possible side effects. The study was approved by the Ethics Board of Al-Azhar University. Included children were subjected to 3 stages: 
Study of the Effect of Repetitive Transcranial Magnetic Stimulation on a Sample of Children...

\section{First stage:}

a- Full medical and psychiatric history in order to pick up and diagnose children with ADHD clinically according to DSM-5 through a designed semi structured interview .

b- Complete physical and neurological examination.

c- Conner's rating scale will be used to

\section{Second stage:} assess the severity of ADHD.

Application of transcranial magnetic stimulation: They received rTMS over the Left Dorso-lateral prefrontal cortex (DL-PFC), at low frequency $1 \mathrm{~Hz}$ and intensity $80 \%$ of motor threshold (10 trains x $10 \mathrm{sec}$, at one-minute interval) every day for five consecutive days. Symptom scores were assessed using Conners Teacher-28 Parent-48 Rating Scales ${ }^{(20)}$ before, after the 5th rTMS session, 2 weeks and 4 weeks after the last session.

Severity of symptoms was classified according to Conners Teacher-28 Parent-48 Rating Scales (20) into two degrees: mild to moderate (66-70) and severe (above 70). Below 66 was considered normal.

\section{Third stage:}

Reassess severity of ADHD symptoms by Conner's rating scales after the fifth session, 2 weeks and 4 weeks from the fifth session.

\section{Inclusion criteria included the following:}

The age range was 6-12years, both sexes were included, diagnosed as ADHD patients by the previously mentioned tools, all patients' parents signed an informed written consent after explanation of the aim of the study and the study details and possible side effects, all patients are not receiving any medical or behavioral therapy for ADHD and all patients Are ADHD patients combined type.

Exclusion criteria included the following: Children with epilepsy, past or family history of seizures, Children with history of brain lesions (post traumatic or any pathology) who may have a lower seizure threshold, Children with any other psychiatric or neurological disease, Children with intracranial metallic or magnetic pieces, Children with implanted medication pump, intra-cardiac line or sever cardiac disease.

\section{Ethical and approval considerations:}

Oral and written consent was taken from parents of children taking into considerations maintaining the confidentiality of the data, consenting to visual footage, publications and most importantly acknowledgement of the potential side effects. And approval of psychiatry department in $\mathrm{Bab} \mathrm{Al}$ Shearia hospital, Al-Azhar University also was taken to do the research.

\section{Statistical analysis:}

All data were collected and analyzed using SPSS program 20 edition using $\mathrm{t}$-test and chi square, $\mathrm{p}$ value is considered significant $<0.05$.

\section{Results}

Table (1): Comparison between means scores of in attention (at base, after fifth session, 2 wks. and 4 wks. after fifth TMS sessions):

\begin{tabular}{|c|c|c|c|c|c|c|}
\hline $\begin{array}{llll}\mathbf{V} & \mathbf{a} & \mathbf{r} & \mathbf{i}\end{array}$ & $\begin{array}{llllll}\mathbf{i} & \mathbf{a} & \mathbf{b} & \mathbf{l} & \mathbf{e} & \mathbf{s} \\
\end{array}$ & $\begin{array}{l}\mathbf{A} \mathbf{t} \text { b a s e } \\
(\mathbf{N}=\mathbf{3 5})\end{array}$ & $\begin{array}{l}\text { After Fifth session } \\
(\mathbf{N}=\mathbf{3 5})\end{array}$ & $\begin{array}{l}2 \text { wks. after fifth session } \\
(\mathbf{N}=\mathbf{3} 5)\end{array}$ & $\begin{array}{l}\text { 4 whs, After session } \\
(\mathbf{N}=\mathbf{3 5})\end{array}$ & $\begin{array}{l}A \quad N O V A \\
p-v a l u e\end{array}$ \\
\hline \multirow[b]{2}{*}{ Means scores } & e $\quad \mathbf{a} \quad \mathbf{n}$ & $\begin{array}{lllll}7 & 3 & . & 0 & 0\end{array}$ & $\begin{array}{lllll}5 & 8 & \cdot & 6 & 3\end{array}$ & $\begin{array}{lllll}5 & 7 & . & 9 & 5\end{array}$ & $\begin{array}{lllll}6 & 5 & \cdot & 1 & 1\end{array}$ & $<0.001 *$ \\
\hline & D & $\begin{array}{llll}4 & \cdot & 7 & 6 \\
\end{array}$ & $5 \quad 9$ & . & $\begin{array}{llll}6 & . & 3 & 8 \\
\end{array}$ & \\
\hline \multirow[b]{2}{*}{ Severity } & $\begin{array}{c}\text { Mild to moderate } \\
\%\end{array}$ & $\begin{array}{l}N=14 \\
4 \quad 0 \quad \%\end{array}$ & $\begin{array}{l}\mathbf{N}=33 \\
94.3 \%\end{array}$ & $\begin{array}{l}\mathrm{N}=32 \\
91 \cdot 4 \%\end{array}$ & $\begin{array}{l}N=27 \\
77.1 \%\end{array}$ & $<0.001 *$ \\
\hline & $\begin{array}{cccccc}\mathbf{S} & \mathbf{e} & \mathbf{v} & \mathbf{e} & \mathbf{r} & \mathbf{e} \\
& & & & \\
& & & & \end{array}$ & $\begin{array}{l}\mathbf{N}=21 \\
6 \%\end{array}$ & $\begin{array}{l}\mathbf{N}=2 \\
5 \quad 7 \%\end{array}$ & $\begin{array}{l}\mathbf{N}=3 \\
8 \quad 6 \%\end{array}$ & $\begin{array}{l}N=8 \\
22.9 \%\end{array}$ & $<0.001 *$ \\
\hline
\end{tabular}

Table no. (1) Shows: Highly statistical significant difference (p-value < 0.001$)$ between means scores of inattention (at base, after fifth session, 2wks. After fifth session and 4 wks. After fifth session). Percentage of severe cases was dramatically decreased immediately and 2 wks. After $\mathrm{r}$ TMS session and start to rise again $4 \mathrm{wks}$. After the fifth session of $\mathrm{r}$ TMS but to lower percent than before $\mathrm{r}$ TMS sessions $(60 \%, 5.7 \%, 8.6 \%, 22.9 \%)$ respectively. 
Table (2): Comparison between means scores of hyperactivity (at base, after fifth session, 2 wks. and 4 wks. after fifth TMS sessions):

\begin{tabular}{|c|c|c|c|c|c|c|}
\hline $\mathbf{V} \mathbf{a} \mathbf{r}$ & $\begin{array}{lllll}\text { a } & b & l & \text { e } & s\end{array}$ & $\begin{array}{l}\mathbf{A} \mathbf{t} \text { b a s e } \\
(\mathbf{N}=35)\end{array}$ & $\begin{array}{l}\text { After Fifth session } \\
(\mathbf{N}=\mathbf{3 5})\end{array}$ & $\begin{array}{l}2 \text { wks. after fifth session } \\
(\mathbf{N}=\mathbf{3 5})\end{array}$ & $\begin{array}{l}4 \text { wks, After session } \\
(\mathbf{N}=\mathbf{3 5})\end{array}$ & $\begin{array}{l}\text { A NOVA } \\
\text { p-value }\end{array}$ \\
\hline \multirow{2}{*}{ Means scores } & $\mathbf{M}$ e a $\mathbf{n}$ & $72 \cdot 29$ & 55.69 & $\begin{array}{lllll}5 & 2 & & 8 & 6\end{array}$ & $\begin{array}{lllll}6 & 3 & 4 & 0\end{array}$ & \\
\hline & \pm & $\begin{array}{llll}3 & \cdot & 9 & 4\end{array}$ & $6 \cdot 7$ & $6 \quad \cdot 7$ & $6 \quad 6 \quad 6 \quad 1$ & \\
\hline \multirow{2}{*}{ Severity } & $\begin{array}{c}\text { Mild to moderate } \\
\text { \% }\end{array}$ & $\begin{array}{llll} & = & & 9 \\
2 & 5 & 7 & \%\end{array}$ & $\begin{array}{llll}\mathbf{N} & = & \mathbf{3} & \mathbf{5} \\
\mathbf{1} & \mathbf{0} & \mathbf{0} & \%\end{array}$ & $\begin{array}{llll}\mathbf{N} & = & \mathbf{3} & \mathbf{5} \\
\mathbf{1} & \mathbf{0} & \mathbf{0} & \%\end{array}$ & $\begin{array}{l}N=31 \\
88.6 \%\end{array}$ & $<0$ \\
\hline & $\begin{array}{c}\mathrm{S} \text { e } \mathrm{v} \text { e } \mathrm{r} \text { e } \\
\%\end{array}$ & $\begin{array}{l}\mathbf{N}=2 \\
74.3\end{array}$ & $\begin{array}{l}\mathbf{N}=\mathbf{0} \\
\mathbf{0}\end{array}$ & $\begin{array}{l}\mathbf{N}=\mathbf{0} \\
\mathbf{0}\end{array}$ & $\begin{array}{l}N=4 \\
11.4 \%\end{array}$ & $<0.001 *$ \\
\hline
\end{tabular}

Table no. (2) Shows: Highly statistical significant difference (p-value < 0.001) between means scores of hyperactivity (at base, after fifth session, 2 wks. After fifth session and 4 wks. After fifth session). Percentage of severe cases was dramatically decreased immediately and 2 wks. After $r$ TMS session and start to rise again $4 \mathrm{wks}$. After the fifth session of $\mathrm{r}$ TMS but to lower percent than before $\mathrm{r}$ TMS sessions. $(74.3 \%, 0 \%, 0 \%, 11.4 \%)$ respectively.

Table (3): Comparison between means scores of impulsivity (at base, after fifth session, 2 wks. and 4 wks. after fifth TMS sessions):

\begin{tabular}{|c|c|c|c|c|c|c|}
\hline $\mathbf{V} \quad \mathbf{a} \quad \mathbf{r}$ & 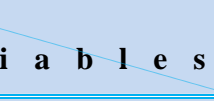 & $\begin{array}{l}A t \quad b \text { a s e } \\
(N=35)\end{array}$ & $\begin{array}{l}\text { After Fifth session } \\
(\mathbf{N}=\mathbf{3 5})\end{array}$ & $\begin{array}{l}2 \text { wks. after fifth session } \\
(\mathbf{N}=\mathbf{3 5} \text { ) }\end{array}$ & $\begin{array}{l}4 \text { wks, After session } \\
(\mathbf{N}=\mathbf{3 5})\end{array}$ & $\begin{array}{l}\text { A } \\
\text { u e }\end{array}$ \\
\hline \multirow{2}{*}{ Means scores } & $\begin{array}{llll}\mathbf{M} & \mathbf{e} & \mathbf{a} & \mathbf{n}\end{array}$ & 73.6 & $\begin{array}{llll}6 & 0 & \cdot & 2\end{array}$ & & 66 & \multirow{2}{*}{$<0.001 *$} \\
\hline & \pm & $4 \cdot 65$ & $6 \quad 35$ & $6 \cdot 6$ & 3.99 & \\
\hline \multirow{2}{*}{ Severity } & $\begin{array}{c}\text { Mild to moderate } \\
\%\end{array}$ & $\begin{array}{l}\mathrm{N}=9 \\
25.7 \%\end{array}$ & $\begin{array}{l}N=34 \\
97.1 \%\end{array}$ & $\begin{array}{llll}\mathbf{N} & = & \mathbf{3} & \mathbf{5} \\
\mathbf{1} & \mathbf{0} & \mathbf{0} & \%\end{array}$ & $\begin{array}{l}N=31 \\
88.6 \%\end{array}$ & $<0$ \\
\hline & $\begin{array}{c}\mathrm{S} \text { e } \mathrm{v} \text { e e } \\
\% \\
\%\end{array}$ & $\begin{array}{l}N=26 \\
74.3 \%\end{array}$ & $\begin{array}{lll}\mathbf{N} & = & 1 \\
2 & 9 & \%\end{array}$ & $\begin{array}{r}=\quad 0 \\
\%\end{array}$ & $\begin{array}{l}N=4 \\
11.4 \%\end{array}$ & $<0$ \\
\hline
\end{tabular}

Table no. (3) Shows: Highly statistical significant difference (p-value $<0.001)$ between means scores (at base, after fifth session, 2wks. After fifth session and 4 wks. After fifth session). Percentage of severe cases was dramatically decreased immediately and 2 wks. After $r$ TMS session and start to rise again 4wks. After the fifth session of $r$ TMS but to lower percent than before $\mathrm{r}$ TMS sessions $(74.3 \%, 2.9 \%, 05,11.4 \%)$ respectively.

\section{Discussion}

In this study we found that:

$>$ According to Conner's teacher-28 parent-48 rating scales, most of children in the sample was suffering from severe in attention, hyperactivity and impulsivity where the percentage was $(60 \%, 74.3 \%$, and $74.3 \%)$ and this was in agreement with study of Abd Alrazik et al. ${ }^{(21)}$ and Osama et al. ${ }^{\text {(22) }}$ where most of children were suffering from severe symptoms.

$>$ There was a statistically significant difference $(p$-value $<0.001)$ between means scores of inattention before the sessions, after the last session, 2 weeks and 4weeks after the last session. The means scores of inattention were (73, $58.63,57.95$, and 65.11) respectively and although it start to rise again 4 weeks after the last session, it didn't reach its pre sessions value. As regard severity, the percentage of severe cases was dramatically decreased 
immediately and 2 weeks after sessions and start to rise again after 4 weeks from the last session but to lower percent than before sessions $(60 \%$, $5.7 \%, 8.6 \%$ and $22.9 \%$ ) respectively and this was in agreement with the study of Abd Alrazik et. al. (21), Osama et. al. ${ }^{(22)}$ where there was a statistically significant difference ( $\mathrm{p}$ value $=0.000$ ) between means scores of inattention before the sessions, after the last session, 2weeks and 4weeks after the last session on SNAP 4 Teacher Parent rating scale. the percentage of severe cases was dramatically decreased immediately and 2 weeks after sessions and start to rise again after 4 weeks from the last session but to lower percent than before sessions $(70 \%, 50 \%, 0 \%$ and $20 \%$ ) respectively. And the study of Gómez et al. ${ }^{(23)}$ where there was a promising improvement in inattention.

$>$ There was a statistically significant difference $(p$-value $<0.001)$ between means scores of hyperactivity before the sessions, after the last session, 2 weeks and 4weeks after the last session. The means scores of inattention were $(72.29,55.69,52.86$, and 63.40) respectively and although it start to rise again 4 weeks after the last session, it didn't reach its pre sessions value. As regard severity, the percentage of severe cases was dramatically decreased immediately and 2 weeks after sessions and start to rise again after 4 weeks from the last session but to lower percent than before sessions $(74.3 \%, 0 \%, 0 \%$ and $11.4 \%$ ) respectively and this was in agreement with the study of Abd Alrazik $\boldsymbol{e t}$. al. (21) Osama et. al. ${ }^{(22)}$ where there was a statistically significant difference (pvalue $=0.000$ ) between means scores of inattention before the sessions, after the last session, 2 weeks and 4 weeks after the last session on SNAP 4 Teacher Parent rating scale. the percentage of severe cases was dramatically decreased immediately and 2 weeks after sessions and start to rise again after 4 weeks from the last session but to lower percent than before sessions $(100 \%, 0 \%, 0 \%$ and $40 \%$ ) respectively. And the study of Gómez et al. ${ }^{(23)}$ where there was a promising improvement in hyperactivity.

$>$ There was a statistically significant difference $\quad(p$-value $<0.001)$ between means scores of impulsivity before the sessions, after the last session, 2 weeks and 4 weeks after the last session. The means scores of inattention were (73.6, $60.2,57.3$, and 66.1) respectively and although it start to rise again 4 weeks after the last session, it didn't reach its pre sessions value. As regard severity, the percentage of severe cases was dramatically decreased immediately and 2 weeks after sessions and start to rise again after 4 weeks from the last session but to lower percent than before sessions $(74.3 \%, 2.9 \%, 80 \%$ and $11.4 \%$ ) respectively and this was in agreement with the study of Gómez $\boldsymbol{e t}$ al. ${ }^{(23)}$ where there was a promising improvement in impulsivity. But not in agreement with the study of Abd Alrazik et al. (21), Osama et al. (22) where there was no improvement in the impulsivity as they used different scale (SNAP 4 Teacher Parent rating scale) for assessment of inattention, hyperactivity and classroom impairment only.

$>$ All previous results weren't in agreement with the study of Kwon $e t$ al. (24) and the study of Le et al. (25) where low frequency $r$ TMS sessions with intensity of 100/110 of motor threshold applied over the supplementary motor area on children with ADHD and Tourette syndrome didn't improve ADHD symptoms. And this can be explained by the difference in samples as the children were suffering from ADHD plus Tourette syndrome and the difference in the used r TMS protocol as regard the intensity and area of stimulation.

$>$ None of the children in the sample experienced significant side effects during the study except for three children who were reported to have mild headache that improved within an hour spontaneously without any treatment.

\section{Conclusion}


This study concluded that repeated sessions of $r$ TMS over left dorso-lateral prefrontal cortex may be safe and an effective way of providing relatively lasting relief of ADHD symptoms especially in children with severe symptoms.

\section{References}

1. Polanczyk GV, Wiicutt EG, Salum GA, Kieling C, and Rohde LA (2014): ADHD prevalence estimates across three decades: an updated systematic review and metaregression analysis. Int $\mathrm{J}$ Epidemol., 43(2):434-42.

2. Kessler RC, Chiu WT, Demler O, Merikangas KR, Walters EE (2005): "Prevalence, severity and comorbidity of 12-month DSM-IV disorders in the National Comorbidity Survey Replication". Arch. Gen. Psychiatry, 62 (6): 617-27.

3. American Psychiatric Association (2013): Diagnostic and statistical manual of mental disorders, fifth edition (DSM5).Washington, D.C. Barker AT, Jalinous R, Freeston IL: Noninvasive magnetic Stimulation of the human motor cortex. Lancet, 1:1106-1107.

4. Bobb AJ, Castellanos FX, Addington AM, and Rapoport JL (2006): Molecular genetic studies of ADHD: 1991 to 2004. Am J Med Genet B Neuropsych Genet., 132:109- 125.

5. Pliszka SR, McCracken JT, Maas JW (2005): Catecholamines in attention-deficit hyperactivity disorder: current perspectives. J Am Acad Child Adolesc Psychiatry,35:264-72

6. Kessler RC, Lenard Adler, Russell Barkley, Joseph Biederman, C. Keith Conners, Olga Demler, Stephen V. Faraone, Laurence L. Greenhill \& Mary J. Howes (2006): The Prevalence and Correlates of Adult ADHD in the United States: Results From the National Comorbidity Survey Replication. Am J Psychiatry, 163:716-723.

7. Barkley RA (2006): Attention-Deficit Hyperactivity Disorder. 3rd Ed. New York: The Guilford Press;. p.770.

8. Christakou A, Murphy CM, Chantiluke $\mathrm{K}$, Cubillo AI, Smith AB, and Giampietro V et al. (2013): Disorderspecific functional abnormalities during sustained attention in youth with attention deficit hyperactivity disorder (ADHD) and with autism. Mol Psychiatr., 18:236-44.

9. Mostofsky SH, Rimrodt SL, Schafer JGB, Boyce A, Goldberg MC, Pekar JJ, and Denckla MB (2006): Atypical motor and sensory cortex activation in attentiondeficit/hyperactivity disorder: a functional magnetic resonance imaging study of simple sequential finger tapping. Biol Psychiatr., 59:48-56.

10. Hart H, Radua J, Nakao T, and MataixCols D, Rubia K (2013): Meta-analysis of functional magnetic resonance imaging studies of inhibition and attention in attention-deficit/ hyperactivity disorder: exploring task-specific, stimulant medication, and age effects. JAMA Psychiatry, 70:185-98.

11. Ikeda T, Kurosawa $M$, Morimoto $C$, Kitayama S, Nukina N (2013): Multiple effects of repetitive transcranial magnetic stimulation on neuropsychiatric disorders. Biochem Biophys Res Commun., 436(2):121-7.

12. Strafella AP, Paus T, Fraraccio $M$, Dagher A (2003): Striatal dopamine release induced by repetitive transcranial magnetic stimulation of the human motor cortex. Brain, 126(12):2609-15.

13. de Andrade DC, Mhalla A, Adam F, Texeira MJ, Bouhassira D (2011): Neuropharmacological basis of rTMSinduced analgesia: the role of endogenous opioids. Pain, 152(2):320-6.

14. Leon-Sarmiento FE, Hanft RT, Bara W, and Hallett $M$, Wassermann $E$ (2002): The influence of visual activation tasks on motor cortex excitability studied with transcranial magnetic stimulation. www.abstract-on line.com/abstracts/AAN

15. Ucles P, Serrano JL, Rosa F (2000): Central conduction time of magnetic brain stimulation in attention-deficit hyperactivity disorder. J Child Neurol., 15:723-8

16. Moll GH, Heinrich H, Trott G, Wirth S, Rothenberger A (2000): Deficient intracortical inhibition in drug-naive children with attention-deficit hyperactivity disorder is enhanced by methylphenidate. Neurosci Lett., 284:1215

17. Arnsten AFT (2009): Toward a new understanding of Attention-deficit hyperactivity disorder Pathophysiology: 
An important role for the prefrontal cortex dysfunction. CNS Drugs, 23(1):33-41.

18. McLeod KR, Langevin LM, Goodyear BG, Dewey D (2014): Functional connectivity of neural motor networks is disrupted in children with developmental coordination disorder and attention-deficit / hyperactivity disorder. NeuroImage: Clinical, 4:566-75.

19. Strafella AP, Paus T, Barrett J, Dagher A (2001): Repetitive transcranial magnetic stimulation of the human prefrontal cortex induces dopamine release in the caudate nucleus. J Neurosci.,21(15):RC157.

20. Conners C (1990): conners' rating scales manual, western psychological services, Los Anglos, California.

21. Abd Alrazik AH, Darweesh ES, Ragah TA (2016): Transcranial Magnetic Stimulation as a new approach in the management of Attention Deficit and hyperactivityDisorder.http://srv4.eulc.edu. eg/eulc_v5/libraries/Start.aspx?ScopeID=1 $. \& \mathrm{fn}=$ ApplySearch $\&$ SearchIdForm\&Scop eIDSelect $=1 . \&$ ItemType \&SearchText $1=\operatorname{Tr}$ anscranial+magnetic\&criteria $1=1 . \& o p r 1=$ and \&SearchText2\&criteria2=1.\&opr $2=$ an $\mathrm{d} \&$ SearchText3\&criteria3=1.\&SearchText FT\&Generation_Term\&BibID\&PublishY ear\&OrderKey

22. Khaled O, Esam S, Khaled A(2006): Therapeutic role of repetitive Transcranial magnetic stimulation in AttentionDeficitHyperactivityDisorder.http://srv4.e ulc.edu.eg/eulc_v5/libraries/start.aspx?fn= ApplySearch\&SearchId=54370304\&frame Name\&PageNo $=12$

23. Gómez L, Vidal B, Morales L, Báez M, Maragoto C, Galvizu R et al. (2014): Low frequency repetitive transcranial magnetic stimulation in children with attention deficit/hyperactivity disorder. Preliminary results. Brain Stimul., 7(5):760-2.

24. Kwon HJ, Lim WS, Lim MH, Lee SJ, Hyun JK, Chae JH et al. (2011): 1-Hz low frequency repetitive transcranial magnetic stimulation in children with Tourette's syndrome. Neurosci Lett., 492(1):1-4.

25. 28. Le K, Liu L, Sun M, Hu L, Xiao N (2013): Transcranial magnetic stimulation at 1 Hertz improves clinical symptoms in children with Tourette syndrome for at least 6 months. JClin Neurosci., 20(2):257-62. 